\title{
Institutionalising restorative justice in the police: key findings from a study of two English police forces
}

\author{
Ian D. Marder
}

Department of Law, Maynooth University, Maynooth, Republic of Ireland

\begin{abstract}
This paper reports the findings of an empirical research project, exploring ongoing attempts to mainstream restorative justice within two English police forces and examining how the police understood and used restorative justice in practice. The findings suggest that two institutional priorities - to satisfy victims and manage the demand on the police's time - strongly influenced the interpretation and practice of restorative justice. This created tensions as police officers who facilitated restorative justice processes used their discretion to determine, on a case-by-case basis, how best to balance these institutional goals with the restorative goal of stakeholder empowerment. These findings illustrate how the police can implement abstract concepts in a selective, discretionary manner, and enhances the limited empirical literature that explains how existing priorities and embedded ways of working within criminal justice agencies, shape their understanding and use of restorative justice in practice. Such knowledge is crucial, if we are to help maximise the benefits and minimise the risks of restorative justice and restorative policing. The article also introduces the concept of 'managed empowerment' to help explain how the tensions between restorative and institutional goals manifested themselves.
\end{abstract}

\section{ARTICLE HISTORY}

Received 14 October 2019

Accepted 14 February 2020

\section{KEYWORDS}

Restorative policing; police discretion; police culture; restorative justice; victims; empowerment

\section{Introduction}

In recent years, governments and criminal justice agencies around the world have shown a growing interest in the ideas and methods constituting restorative justice. This interest has been both normative and practical, with restorative justice interpreted and implemented differently in different countries, depending on the legal system, the stage of the criminal justice process at which it is used, and the attitudes, goals and priorities of those in a position to determine how restorative justice should operate.

Mixed results have emerged from empirical reviews of implementation. Rigorous studies indicate that voluntary, facilitated dialogue between victims and offenders can produce more satisfaction than court while instigating or supporting offender desistance and victim recovery (e.g., Angel et al., 2014; Shapland et al., 2011; Sherman et al., 2015; Strang et al., 2013). The results are strongest when participants experience processes as empowering and fair, creating space for their active participation in dialogue and 
outcome determination (Crawford, 2010). However, research also indicates that mainstreaming restorative justice within criminal justice operations can result in hybrid narratives and practices that deviate from these core restorative principles (Crawford, 2006; Daly, 2003; Hoyle et al., 2002; Rosenblatt, 2015).

The consequent risks for participants are contingent on the setting. For example, police forces may expect their officers to facilitate restorative justice, despite a cultural aversion to the approach or a lack of skills and resources to adhere to best practice (Walgrave, 2012). At best, police officers may use their restorative training to empower victims, offenders and other stakeholders to participate voluntarily in a respectful dialogue and in determining fair outcomes that meet all parties' needs (Clamp \& Paterson, 2017). At worst, the police may use their discretion to disempower vulnerable citizens further by coercing participation, stigmatising, sidestepping due process rights or imposing their preferred outcomes (Cutress, 2015; Larsson et al., 2018; Vanfraechem, 2009). It is vital, therefore, to scrutinise restorative policing empirically, establishing how the police understand and use restorative justice in practice and the implications for citizens and operational policing.

This paper reports the main findings from a recent empirical project that explored the institutionalisation of restorative justice in two English police forces. One force (Durham Constabulary) trained the majority of frontline officers to facilitate face-to-face dialogue between victims and offenders in the form of restorative conferences, and provided at least some restorative justice training to all officers and non-operational staff, at all levels. At the second force (Gloucestershire Constabulary), training reached only frontline officers, a minority of whom received instruction in face-to-face conferencing. Despite these differences, both forces expected all trained, frontline officers to facilitate some form of restorative justice within their day-to-day roles.

The researcher collected statistics and official documents and conducted 44 semistructured interviews; 16 trained officers - or 'police facilitators' - and six managers were interviewed at each force. The findings indicate that institutional priorities and ways of working shaped the police's understanding and use of restorative justice. While some participants may have experienced practices as empowering, officers often described using their discretion to keep control over processes, as they sought to achieve organisational goals by satisfying victims and managing the demand on their time. The paper borrows the concept of 'managed empowerment' from the healthcare literature (Davey, 2015) to help explain this phenomenon and situate it within previous findings on the gap between theory and practice in restorative justice.

After defining restorative justice and the potential effects of its institutionalisation, the article highlights the tensions between restorative justice and operational policing. It notes the significance of participant empowerment in the former and police discretion and culture in the latter, drawing on the literature regarding the institutionalisation of other policing philosophies to contextualise the environment in which restorative policing occurs. The next sections outline the national framework for restorative policing in England and the current study's cases and methods, before the remainder of the paper discusses its key findings. These indicate that the respondents understood and used restorative justice principally as a tool to satisfy victims and manage demand - two key priorities in English policing at that time - and used their discretion to retain control over restorative processes to balance policing and restorative goals. It is argued that 
institutional incentives to manage participants' empowerment may help explain the gap between theory and practice that emerges as agencies with entrenched rationales institutionalise restorative justice.

\section{Institutionalising restorative justice}

This research adopted a dialogic approach to restorative justice as a process that enables stakeholders to an offence to communicate with each other about the harm done and participate in outcome determination (Hoyle, 2010; McCold, 2000; Restorative Justice Council, 2011). This notion of restorative justice as a process through which justice can be done, provides clear, observable boundaries to the concept, enabling its empirical examination and comparison with other approaches (Daly, 2016). As noted in the introduction, this also denotes the model of restorative justice - dialogue between victims and offenders - for which there is the most robust evidence of the benefits for participating victims and offenders.

In the context of this research, the dialogic approach was especially appropriate because the study examined how and why police officers use restorative processes in practice. Others have formulated broader concepts of a 'restorative policing' in which all police activities, goals and structures are underpinned by relational thinking and focus on repairing harm and enabling stakeholder participation (Bazemore \& Griffiths, 2003; Lofty, 2002; Weitekamp et al., 2003). Recently, Clamp and Paterson (2017) developed a model of restorative policing in which it represents a new policing objective: to 'promote beneficial forms of social capital' (p. 119, emphasis in original). While these are valuable contributions to ongoing discussions about the police's fundamental purpose, it was beyond the scope of this study to engage meaningfully with such a broad conception of restorative justice. Rather, the research falls into the empirical tradition of Hoyle et al. (2002), Stockdale (2015), Shapland et al. (2017) and others who study how police officers understand and use restorative processes in practice.

Such research is necessary because restorative justice is conceptually elastic, potentially meaning 'all things to all people' (McCold, 2000, p. 357). Its ambiguity means that restorative justice can be shaped and moulded by the institutional context within which it is implemented, in ways that affect the extent to which its benefits can be realised. Facilitators must decide how and when to offer restorative justice, the extent of any preparatory or follow-up work, how to enable the parties to communicate and contribute to outcome decisions, and how to speak to and treat the participants throughout the process (Chapman, 2012; Laxminarayan, 2014). Research suggests that the process is most likely to be successful if it involves dialogue and collective decision-making among stakeholders who feel well-prepared, respected, included and fairly treated throughout (McCold \& Wachtel, 2002; Shapland et al., 2011; Sherman et al., 2015). In other words, the impact of a restorative process depends partly on its facilitator's ability and inclination to engage in 'principled facilitation' (Chapman, 2012, p. 80) by exercising their discretion in accordance with restorative principles.

Yet, restorative justice neither exists in a vacuum, nor is it delivered by robots. Rather, mainstreaming restorative justice within criminal justice typically involves justice agencies and practitioners being responsible for making and implementing policies, funding and overseeing practices and, often, facilitating restorative processes (O'Mahony \& Doak, 
2017). As a result, restorative justice is interpreted and used in a manner which reflects entrenched rationales and ways of working, and prioritises system-focused, rather than restorative, principles and goals. When implemented within the existing justice process, restorative justice is 'received and perceived by highly developed agencies with strongly institutionalised other rationalities' (Blad, 2006, p. 108). The resulting practices and narratives can hybridise the values of criminal and restorative justice and deviate from the principles that act as safeguards for participants or help explain its effectiveness. Far from supporting citizens to be empowered and respected and to make decisions collectively and autonomously, restorative justice, when co-opted by system rationales, might provide only a limited challenge to the state's power, or even allow agencies and professionals to consolidate their control or impose their will on citizens (Crawford, 2006; Karstedt, 2011; Richards, 2011). This may explain why restorative justice, when mainstreamed within existing justice agencies, often achieves more modest results than its advocates might hope, or its 'nirvana story' (Daly, 2003, p. 234) suggests. As Laxminarayan (2014) argued: 'the mainstreaming of restorative justice may lead to a clash between safeguarding the quality of restorative justice and institutionalising these programmes' (p. 43).

Identifying the nature and implications of any such gap between the theory and practice of restorative justice, requires a detailed consideration of the rationales present within a specific context, in relation to those which constitute the restorative framework. In the case of frontline police officers facilitating restorative processes, operational policing must itself be examined.

\section{Tensions between restorative justice and operational policing}

The risks and tensions inherent in the mainstreaming of restorative justice in operational policing reflect the unique role which police officers occupy in society. Lipsky (2010) argues that, like other frontline practitioners, the police exert power and allocate benefits and sanctions on behalf of the state, and have considerable discretion when doing so. However, three factors combine to differentiate the police from other public servants: the breadth of the tasks they are expected to undertake; the urgency with which they are required to act; and the lawful, coercive force that they are entitled to use. Their range of responsibilities is exemplified by Wilson's distinction (Wilson, 1968) between the task of 'law enforcement', in which the police invoke the criminal law, use legal powers and apply legal sanctions, and that of 'order maintenance', in which they provide a wide range of support and interventions for and among citizens (p. 407). High public expectations also have a temporal quality: Bittner (1990) held that the police are expected to intervene in any and all situations 'that ought not to be happening and about which someone had better do something now' (p. 249). Finally, H. Goldstein (1977) highlights the importance of police officers' legal powers, explaining that their ability to arrest, search and detain, inter alia, means that their function is 'an anomaly in a free society' (p. 1).

It is necessary to understand these characteristics of operational policing because they represent the context within which its most important feature - police discretion - is exercised. Police discretion arises from the requirements efficiently to balance competing tasks and pressures, interpret ambiguous provisions and complex human situations, and decide when to invoke the criminal law. In other words, police officers have considerable 
autonomy to determine what to prioritise when, and whether to use their legal powers (Lipsky, 2010). Crucially, discretion is augmented by the low-visibility and low-scrutiny environment in which police officers operate, especially when 'on the street' (J. Goldstein, 1960; McConville et al., 1991), which is why police discretion is highest on the frontline (Wilson, 1968). In England, where this research took place, police discretion is guarded especially closely as it also arises from the doctrine of 'constabulary independence', referring to the officer's 'legal right and duty to enforce the law as she sees fit' (McConville et al., 1991, p. 2).

This unique position necessitates regulation and accountability to constrain the police's use of powers and promote a rights-based framework for operational policing. Yet, it is a global truism that the police's low-visibility discretion makes it difficult to regulate their behaviour through law and policy (Reiner, 2010). In practice, police discretion is structured primarily by the occupational police culture. This is defined as the blend of values, priorities and unwritten rules and principles of conduct that endure within the profession and emerge partly from the setting in which the police operate, and partly from their 'knowledge' of how policework should be done, which is passed between generations of serving officers (Chan, 1996).

This has implications for police involvement in restorative justice. As noted earlier, the success of restorative justice is dependent on choices made by the facilitator. Simply referring to a practice as 'restorative', or even enabling a victim and an offender to communicate, is not enough. Facilitators must also create the conditions where the parties feel prepared, respected, fairly treated and enabled fully to express themselves and participate meaningfully in determining outcomes. Restorative justice is most likely to satisfy its participants' needs when they experience the process as empowering and procedurally just, insofar as they feel able to exert influence over what happens (Richards, 2011; Zimmerman, 1995) and believe that the process was conducted respectfully, impartially and not dominated by one party (Tyler, 2006). However, tensions arise when the police's responsibilities and 'ways of working' - the patterns of police behaviour that reflect their cultural assumptions (McConville et al., 1991) - come into conflict with these principles of best practice.

Studies have found deficiencies in the manner in which the police deliver restorative justice, reflecting commonly observed characteristics of police culture. For example, twoway communication between victims and offenders is widely seen as the defining characteristic of a restorative process. However, researchers often find that police facilitators fail to invite the victim to participate, or offer only to act as a go-between, in order to achieve a 'quick-fix'. This was true for studies both of police-led 'restorative cautions' (Hoyle et al., 2002; O'Mahony \& Doak, 2013) and of 'Level 1 RJ' (Clamp \& O'Mahony, 2019; Cutress, 2015; Larsson et al., 2018; Meadows et al., 2012; Shapland et al., 2017), to which we return later. Similarly, the police often marginalise families and other indirect stakeholders in restorative justice by failing to enable their participation (Stockdale, 2015). These findings reflect the police's cultural bias towards using their control to achieve quick, pragmatic solutions, research long having illustrated that the police are task- rather than process-oriented and prioritise efficiency over other concerns (Skolnick, 1966). This drive for efficiency means that the relational, educational and legitimacy-related benefits of dialogue are neglected, and a resolution- (rather than needs- or participation-) focused approach is prioritised. This also reflects the embedded nature of operational practices: 
rather than aiming for 'fully' restorative processes, the police may just integrate elements of the restorative framework into activities - such as cautioning and informal resolution which they already do.

Even when police facilitators do enable dialogue between victims and offenders, there is evidence that some may disempower participants by dominating the dialogue or failing to treat the parties equally and respectfully. For example, Hoyle et al. (2002) observed some officers using restorative cautions as an opportunity to 'pursue their own deterrent agenda or sideline the interests of the victim' (p. 17). In another study, police facilitators dominated discussions if they felt the need to 'draw out uncooperative offenders' (Kenney \& Clairmont 2009, p. 299), despite evidence that restorative processes are most effective when facilitators use non-verbal encouragements and limit their spoken interventions (Daly, 2003; Shapland et al., 2011). This reflects the occupational propensity to exert authority and maintain control over situations and citizens especially suspects, offenders and 'undeserving' victims (McConville et al., 1991). Similarly, Gray (2005) found that some officers use the facilitation role to blame or shame offenders in a degrading manner. This may reflect police perceptions of offenders as 'police property' (Waddington, 1999), and thus as people worthy of repression or from whom they can extract deference (Choongh, 1998). This is especially problematic considering the racial and socioeconomic dimensions of cultural assumptions about who the police should trust or target, and who is deserving of their support or sympathy (Bowling et al., 2001; Choongh, 1998; McConville et al., 1991). Similar arguments could be made about research findings which show police officers putting pressure on people to participate in restorative processes (e.g., McCold, 1998; O'Mahony \& Doak, 2004) or to accept certain outcomes (e.g., Cutress, 2015; Hoyle et al., 2002; Matthews, 2006). This deviates from the core principles of voluntariness and participant-led outcome determination, respectively, but reflects the police's role and habit of exerting control through implicit or explicit threats of coercion (Reiner, 2010).

The point is that the restorative policing literature reflects the findings from the wider policing research: the police use their authority and legal powers to control what happens in police-citizen interactions, and exercise their discretion to achieve police-defined goals. Yet, these elements of police culture are anathema to the restorative ideal which is predicated on practitioners devolving control over deliberations and decision-making processes to those directly involved in and affected by a given crime or conflict. Simply put, officers must act differently to facilitate restorative justice effectively. As Clamp and Paterson (2013) argued:

Restorative justice alters the roles and responsibilities of individuals within the process. [...] Officers [must] act as facilitators and silent stakeholders rather than as decision-makers, a process which requires police officers to interpret and undertake their role in innovative ways. (p. 300)

The need to reimagine the role of frontline practitioners may apply across all efforts by public agencies to deprofessionalise decision-making (Davey, 2015). Yet, we might expect the police to be particularly resistant to relinquishing control. Not only are they accustomed to being able to determine what will happen to citizens (with their own goals and those of their organisation in mind), but their work is characterised by 'habitual action' 
(Chan, 1996, p. 113), further raising the possibility that officers might find it hard to make such radical behavioural changes.

This is not to say that many police officers cannot facilitate well. Indeed, one of the most famous and rigorous studies to identify the benefits of restorative justice included many police-led conferences in its sample (Shapland et al., 2011). Shapland et al. (2011) and Hipple and McGarrell (2008) identified no significant differences between participants' views of police and non-police facilitators; others have found that the vast majority of participants in police-led restorative processes believed that the facilitator was impartial and the process was fair (Hoyle et al., 2002; Larsen, 2014; McCold, 1998; Sherman et al., 1998). Larsson et al.'s study (Larsson et al., 2018) on police-facilitated restorative justice suggested that different officers might be more or less restoratively inclined, depending on their willingness to listen to every party's side of the story and treat each party with respect.

The problem here is not that police officers are a homogeneous group, unable to resist the influence of police culture or use their discretion in creative ways (Chan, 1996). Rather, the difficulties lie in the process by which ambiguous concepts, like restorative justice, are (re)configured and institutionalised across their organisations. As Garland (2001) noted, restorative justice sits among the recent justice developments that do not clearly fall within a discrete ideological category. This can confuse policymakers and practitioners who attempt to locate new ideas within existing traditions and understandings (Boutellier, 2006). In a force that trains all frontline officers to use restorative justice, officers at all levels must engage in a hermeneutical process in which they determine what restorative justice means and for whom it exists. As restorative justice is embedded through training and policy, varied and culturally contingent interpretations by leaders, managers and early adopters will cascade throughout the force, influencing officers who also retain the discretion to interpret and use restorative justice according to situational or individual factors. This permits, and may even incentivise, individuals to place emphasis on or disregard different elements of the restorative framework.

Studies on community, problem-oriented and evidence-based policing similarly find that their ambiguity and imprecise formulation make them malleable and susceptible to co-option by existing rationales. For example, whereas community policing was originally envisaged as a decentralised approach in which the police engage citizens about their priorities and promote police-community relationships and cooperation (Skogan, 2006; Tilley, 2003), these 'softer' activities are often sidelined as they clash with police culture and performance management (Fielding \& Innes, 2006; Innes, 2005). In the United States, for example, where the need to be 'tough on crime' was the mantra of the era, early adopters of community policing typically implemented more visible, but still highly coercive, reactive and centralised, practices (Oliver, 2000; Skolnick \& Bayley, 1988). Problem-solving and evidence-based policing have also been shaped by existing rationales: the former is often used to enhance reactive approaches and close cases efficiently, with its proactive elements neglected (Boba \& Crank, 2008; Ikerd, 2007); the latter often focuses on 'value for money' and technological development at the expense of normative or rights-based research evidence (Greene, 2013; Sherman, 2013).

To the extent that the police interpret and apply these ideas in ways that reflect existing priorities, their impact on police behaviour may be limited. The police can easily disregard any element of a philosophy that they see as difficult to achieve or in tension 
with existing goals. That restorative justice might involve bringing the victim and offender into communication raises the stakes of this dilution. This concern has led some to question whether it is appropriate for police officers to facilitate (Vanfraechem, 2009; Walgrave, 2012). Others conclude that the police are well placed to do so, if properly trained and supervised (Hipple \& McGarrell, 2008; Larsen, 2014; Shapland et al., 2011). Others, still, promote restorative policing as a coherent moral and methodological framework with which to realise community and problem-solving policing goals (Clamp \& Paterson, 2017; Weitekamp et al., 2003). Given the growing interest in restorative policing, we must analyse the effects of its institutionalisation to determine how best to maximise its benefits and minimise its risks.

\section{Restorative policing in England and Wales: the national context}

Following many years of experimentation with restorative policing in England and Wales (Shewan, 2010), local leaders retain the discretion to decide force policies on restorative justice and officers are not legally compelled to deliver it at all, or in any particular way (Home Office, 2013). Moreover, a nationwide funding boost from 2013 enabled officers in many areas to refer suitable cases to local, external services (Institute for Criminal Policy Research, 2016). Consequently, the 43 local forces differ considerably in terms of the degree to which they train their officers in restorative justice and under what circumstances, if any, they expect or permit their officers personally to facilitate restorative processes (Clamp and O'Mahony, 2019).

The Association of Chief Police Officers' guidance on police-led delivery of restorative justice (Association of Chief Police Officers, 2011) further enables discretion at the local and individual levels. It provides a flexible framework within which forces and officers can situate their involvement in facilitation, defining restorative justice as:

A victim-focused resolution to a crime or a non-crime incident [which] holds offenders, either young people or adults, directly accountable to their victims and can bring them together in a facilitated meeting. (p. 4)

This supports the positioning of restorative justice as a 'service for victims', an important trend in England (Gavrielides, 2017) which is discussed later. Moreover, this definition does not require a practice to involve dialogue between the parties to qualify as restorative. Rather, restorative justice need only be 'victim focused', a notion that was left undefined, but which acts to water down the UK government's explicitly dialogic definition (Ministry of Justice, 2013). This level of ambiguity in what does and does not qualify as restorative justice is consistent with that which typically characterises police guidance, leaving it open to interpretation by forces and officers (McBarnet, 1981; Sanders et al., 2010).

The document further dilutes restorative justice by outlining a tripartite - Level 1/2/3 framework of practices. Levels 2 and 3 refer to restorative conferencing, a dialogic practice, pre- or post-court, respectively. Level 1/'Street $\mathrm{RJ}^{\prime}$, however, is defined as an 'instant or on-street disposal where police officers or PCSOs use restorative skills to resolve conflict in the course of their duties' (Association of Chief Police Officers, 2011, p. 7). 'Restorative skills', like 'victim-focused', is not defined and further departs from the need for restorative justice to incorporate dialogue and collective decision making among 
stakeholders. Other studies (e.g., Cutress, 2015; Larsson et al., 2018; Walters, 2014) found that the flexibility of Level 1 RJ has led to its broad interpretation by forces, empowering officers to determine the extent to which they apply restorative principles on a case-bycase basis. In other words, it legitimises an understanding of restorative justice that does not require close adherence to best practice to record and frame a resolution as restorative in nature (Stockdale, 2015). This study explored the implementation of ACPO's framework in the context of police discretion, finding evidence that institutional priorities influenced the ways in which the police understood and used restorative justice in practice.

\section{The current study}

This paper presents key findings from a recent study that investigated the institutionalisation of restorative justice in two English police forces. It took place in Durham and Gloucestershire Constabularies, two of the 43 local police forces in England and Wales. This section contextualises the findings by explaining why each force was selected and outlining the strategic approach to restorative policing in each area, including statistics on training and use. ${ }^{1}$

Durham and Gloucestershire Constabularies were selected because they were comparable in several ways. Firstly, in relation to their general characteristics, they were among the smaller, more rural forces, with medium-sized urban conurbations. Secondly, these Constabularies served similar population sizes: around 513,000 and 596,000, respectively, according to the 2011 Census. Thirdly, they had similar numbers of police officers, with 1131 in Durham and 1123 in Gloucestershire, as of March 2015 (Home Office, 2017). Fourthly, they had comparable rates of crime and anti-social behaviour, albeit both ran about 10\% higher in Durham than in Gloucestershire (Her Majesty's Inspectorate of Constabulary [HMIC], 2016).

Perhaps most importantly, both forces implemented restorative justice in a significant way through staff training, policy and a requirement that all 'community resolutions' - the lowest-tariff out-of-court disposal available in England - must involve either Level 1 (street) or Level 2 (conferencing) restorative justice. Yet, while both restorative justice projects were ambitious, they operated at different scales. Both forces trained their officers in some form of restorative justice. However, Durham trained around 430 officers to facilitate Level 2 conferences and all other staff $(\sim 1650)$ to Level 1, while Gloucestershire only trained around 45 officers to Level 2, and the remaining frontline officers ( 620 people) to Level 1. Gloucestershire also did not train its police staff or senior officers in restorative justice.

The use of restorative justice mirrored these differences. Statistics collected from force databases showed that Durham used restorative justice 2796 times in the eleven months to July $2015{ }^{2}$ while Gloucestershire only saw 672 cases in the same period. This also reflects the fact that officers in Durham had to consider offering restorative justice in all cases, irrespective of whether or not the suspect was prosecuted. Officers were required to record the reasons why they did not offer restorative justice in a given case to encourage greater use, and some officers received Level 3 training to facilitate in more serious cases. In contrast, officers in Gloucestershire could only deliver restorative justice alongside community resolutions. It was not possible to obtain data on the distribution of 
restorative justice use among officers, although interview data, explained in the following section, suggest that this was uneven.

Differences between the force's training and use of restorative justice reflected its role in broader strategies. In Durham, the Chief personally drove restorative justice to change force culture. Training materials and internal guidance referenced a desire to create 'a restorative organisation', and many interviewees understood restorative justice as part of a wider strategy to enable citizen participation in problem solving. In contrast, no documents or respondents in Gloucestershire spoke of creating a 'restorative organisation', reflecting a more limited strategy which focused on victim satisfaction with informal disposals. This correlation, between the level of commitment to restorative justice by force leaders and its use in practice, is consistent with previous research on leaders' role in implementation (Hoyle, 2011).

The final key difference between the forces was in their framing of restorative justice. In Durham, guidance documents, training materials and respondent policymakers universally characterised restorative justice as victim-offender dialogue. Even at Level 1, Durham expected and trained officers to offer the parties the chance to communicate with each other directly. In contrast, few officers in Gloucestershire were trained to facilitate a dialogue, and their guidance and recording framework for Level 1 - a form on which officers were required only to record the parties' details and the outcomes agreed - did not encourage them to provide opportunities for dialogue. Officers' understanding of restorative justice reflected this difference: in Durham, they were more likely to define restorative justice as dialogue, whereas in Gloucestershire, they were more likely to define it as achieving any outcome to which all parties agreed, illustrating the role that organisational narratives, policies and training can play in shaping practitioners' interpretations of the concept.

What officers from both forces had in common was that they described understanding and using restorative justice in a way that was victim-focused and helped manage the demand on their time, as well as facilitating practices actively to achieve these goals. The prominence of these themes across the data from both forces, despite differences at the strategic level, merits their exploration. Following a brief methodology, the remainder of the paper focuses on the role that institutional priorities may play in explaining these similarities.

\section{Methodology}

This section outlines the data underpinning this paper and the sampling of interviewees from each force. The datasets from which this paper draws include:

(1) 44 semi-structured interviews, including 32 with police facilitators who facilitated at least one case in the previous year and 12 with police policymakers and managers who oversaw or developed restorative justice (divided equally between the two forces);

(2) 94 official documents (42 from Durham; 52 from Gloucestershire) pertaining to the implementation of restorative justice (including the training and guidance documents referenced in the previous section); and 
(3) descriptive statistics from force databases on restorative justice training and delivery, presented in the previous section.

The police facilitators interviewed for the research included both warranted officers and Police Community Support Officers (PCSOs), who have some powers (including to deliver community resolutions), but who cannot arrest or search suspects. Nine of the 16 facilitators interviewed in Durham, and two of 16 in Gloucestershire, were PCSOs. All police facilitators were required to have delivered restorative justice at least once in the previous twelve months to participate in the study. This criterion aimed to ensure that participants had facilitated under the current policy framework and could recall case details. Interviewees were asked in how many cases they had used restorative justice in the previous year, with answers at both forces ranging from once or twice, to 'all the time' and ' $20+$ ', or similar. The policymakers and managers interviewed included similar numbers of senior leaders, middle managers and police staff from each force. These respondents were snowball sampled among those with direct involvement in restorative justice implementation. The researcher conducted the interviews, and collected most other data, in May and June of 2015; some of the documentary and statistical data were collected shortly before or after these dates.

This study contributes to a growing literature which examines how restorative justice is understood and experienced by its facilitators (e.g., Crocker, 2016; Murray, 2012). Researchers caution that police anecdotes may reflect mythology, rather than reality (Bayley \& Bittner, 1984), but officers' accounts can boost our understanding of the principles, reasoning and priorities that underpin their decision-making (Reiner, 2010; Shearing \& Ericson, 1991). One limitation of the data is that the police facilitators interviewed include an unknown ratio of officers who responded to internal emails seeking participants (indicating a self-selection bias), and who were asked to participate by each force's restorative justice manager (indicating a gatekeeper selection bias). Still, there are few better ways to explore police understandings of their work than to ask them. What a qualitative framework lacks in representativeness, it makes up for in its ability to identify ambivalence and, in this case, establish the extent to which elements of the police culture or restorative framework were accepted or rejected at an individual level.

\section{Key findings}

The study found that police facilitators could exert control over both the process and outcome of restorative justice to achieve police-defined goals. Specifically, the evidence suggests that institutional imperatives to satisfy victims and manage the demand on the police's time shaped the understanding and use of restorative justice, as described and rationalised by police respondents. This section investigates the ways in which these goals shaped restorative justice in the forces. It then introduces the concept of 'managed empowerment' to help conceptualise how and why the police sought to balance institutional and restorative goals. 


\section{Restorative justice as victim-focused}

I don't know if I should say this or not: do we really care how the offender feels at the end of it? Police facilitator, Durham

Research has long suggested that the police instrumentalise victims to achieve policedefined goals (Crawford, 2000). However, recent years have seen a growth in the police's responsibilities towards victims (Hoyle, 2011) alongside the proliferation of a 'service culture' (Reiner, 2010, p. 248) and a politicised 'victim-focused' agenda (Duggan \& Heap, 2014). In England and Wales, victims are now among the criminal justice system's 'customers' (O'Malley, 2004) and have certain rights to which the police must attend (Ministry of Justice, 2015). Moreover, victim satisfaction has become a key indicator on which police forces are measured nationally (HMIC, 2014). Successive British governments have entangled restorative justice with these developments, framing it as one among many new 'victim-focused' services (Acton, 2015).

This provides important context to the findings. Advocates see restorative justice as able to break down the false dichotomy of 'victim' and 'offender', drawing out and working with 'thick' (i.e. layered and complex) stories (e.g., Dzur, 2016). Whether one considers the facilitator's role to be 'neutral' (Vanfraechem, 2009), 'impartial' (Mackay, 2006) or 'multi-partial' (Karp, 2015), restorative justice theorists generally agree that facilitators should show equal concern for both parties' needs in order that these may be expressed and met (Braithwaite, 2002; Schiff, 2007). This contrasts with a criminal law that presents justice as a zero-sum game, represses ambiguity and squeezes multifaceted situations into blunt, dichotomous categories - a process in which the police play a central role (McConville et al., 1991). It also contrasts with the recent narrative in England and Wales stating that restorative justice is a service for victims, and thus does and should prioritise victims over offenders (Gavrielides, 2017).

In this study, police understandings and use of restorative justice reflected its inclusion within this 'victim-focused' narrative. Its interpretation as something that is largely 'for' victims was prevalent in both forces: this was implied within policies, stated prominently among policymakers' strategic goals and in practitioners' motivations for using restorative justice, and apparent in descriptions of practice. In terms of written policies, for example, Gloucestershire's internal guidelines defined restorative justice, as per ACPO's guidance, as a 'victim focused resolution' (p. 2), while Durham designed a facilitation aid for officers (known as a 'script') which prioritised opportunities for victim expression, relative to more balanced versions of the script used elsewhere (Chapman, 2012).

Policymakers and managers in both forces mostly also framed their impetus to develop restorative justice primarily in terms of the victim:

It gives victims the voice that they've always deserved, to have an element of control when some feel that they haven't had that voice in the criminal justice system. So, it's empowered them to have a greater say. They are paramount in my opinion, and also in our vision for policing locally. Police policymaker, Durham

Similarly, in Gloucestershire, one policymaker stated that 'The whole business about it being victim-centred has got to be the right thing to do,' while another explained: 
The important thing is about working with victims and putting the focus on the victims of crime. For me, that's where restorative justice should be, it should be focused on victims. Police policymaker, Gloucestershire

By implication, restorative justice does not focus equally on meeting the offender's needs. Most police facilitators seemed to concur, with one from Durham stating: 'Whether it's Level 1 or 2, it's all about the satisfaction of the victim'. Likewise, one of their colleagues reasoned:

I get that the offender is wholly part of that situation, and there will probably be some realisation and some learning for the offender, and that potentially reduces their offending going forward, but, fundamentally, it starts with the victim. Everything else is secondary or tertiary to that, in my view. Police facilitator, Durham

In Gloucestershire, officers similarly expressed that they were primarily concerned about victims, with one stating: 'Potentially both parties get something out of it but, ideally, the victim is pleased with the outcome and has got the justice they want'. The suggestion is that one can measure the success of the process primarily according to the victim's experience.

Descriptions of practice mirrored this imbalance. For example, many respondents reported giving victims more opportunities than offenders to participate in outcome decisions at Level 1 and Level 2. At Level 1, police facilitators from both forces described suggesting outcomes to victims or asking victims what they wanted the outcomes (such as reparation) to be, before presenting that request to the offender as their opportunity for a community resolution. This could have led to some offenders receiving a higher-tariff disposal solely on the basis that they were unable or unwilling to comply with their victim's demands, which may or may not have been proportionate. Similarly, some respondents described agreeing outcomes with victims during the preparation for Level 2 conferences and presenting those to offenders as the conditions of their participation (and thus, of their diversion from a higher-tariff disposal or prosecution). Yet, determining outcomes without offender input means that offenders may have been prevented from having their own needs met by the process, increases the likelihood that they experienced the outcomes as imposed, and removes the safeguard of their participation in the deliberations.

This is not to say that respondents uniformly discounted offenders in their understanding of the purpose of restorative justice. Many discussed how diversion was positive for offenders, or that the process might help reduce reoffending. Still, the understanding of restorative justice as victim-focused may have led to particular risks for offenders, if denied principled facilitation in the service of victim satisfaction. For example, many officers reported efforts to 'sell' restorative justice to prospective participants, but for victims, this 'sale' would focus on the potential benefits, while offenders were more likely to receive veiled threats about worse alternatives:

If I ever had anybody that refused to take part in the RJ, then, obviously, the carrot or the stick. The stick is: 'Ok, you get arrested or, at least, I report you and you go to court. It's up to you. This is actually your opportunity, if you want to take your chance in court, then by all means.' Police facilitator, Gloucestershire

Research on police practices illustrates that people feel under pressure to agree to any request by the police (Delsol \& Shiner, 2006). Thus, this approach could act to magnify any 
pressure under which offenders felt to consent to what is supposed to be a voluntary process, exposing themselves to whatever outcomes are decided in their absence, while losing the opportunity to have the evidence and any legal defences tested in court. One officer reported seeking to avoid putting pressure on offenders to participate, but expressed the desire to do so, linking this to being 'victim-focused':

A couple of times I wanted to deal with the restorative approach, and either I couldn't, or I didn't get the outcome that I wanted for the victim, and I felt that we could do things a little differently. Maybe, not force people's hands, but a bit more pressure on offenders to engage in a restorative approach. Sometimes they don't wanna engage in it and I think, being victimfocused, I feel like I've let the victim down. Police facilitator, Durham

The risk of a victim-focused narrative, as illustrated by these quotations, is that it may create or reinforce a desire to deviate from restorative principles, including voluntariness, equality of concern and collective ownership of decision making. Seemingly, some respondents saw these principles as expendable - at least, on the offender's side, in the pursuit of victim satisfaction - despite their crucial rolein safeguarding offenders and ensuring that the process works for them.

Implicit within these data is the enduring allusion to a zero-sum game: that one must necessarily prioritise one party, and the victim is the most appropriate person to prioritise. This mirrors the tensions between the equality of concern promoted by restorative justice proponents, and the rationales entrenched in the criminal justice process, in which those presenting as victims deserve more support than those presenting as offenders, any benefits to one must come at the expense of the other, and there are necessarily winners and losers from the justice process. It is perhaps unsurprising if police officers have difficulty reconciling the notion that restorative justice can meet the needs of all parties, with the adversarial, 'winner-takes-all' system in which they have long operated, the underlying assumptions of which are propagated by their institutional culture and wider society.

It is especially significant that this study found a substantial foregrounding of victims, as police facilitators in previous English studies were found to focus on deterring or rehabilitating offenders (e.g., Hoyle et al., 2002) or on expediency (e.g., Cutress, 2015; Walters, 2014) at the expense of victim engagement. The current findings may reflect either a rhetorical or a genuine shift towards prioritising victims, whether inspired by restorative justice training or by changes in discourse, policy and performance indicators. That the police have long ignored victims' needs, even in the context of early restorative policing experiments, could justify this emphasis on victims in restorative justice implementation. Without a corresponding reconsideration of the position of offenders, however, restorative justice may fail to undermine the low priority afforded to offenders' needs and be open to abuse by punitive victims and police. Using restorative justice to 'prioritise the rectification of wrongs by one party' (O'Malley, 2006, p. 229) risks individualising offending in isolation of its social context, which Karstedt (2011) labelled as the salient risk of restorative justice under neoliberal conditions. Some officers expressed the belief that the process was mutually beneficial, but any focus on offenders tended to be actuarial - i.e. reducing the risk of reoffending - rather than reintegrative, empowering or supportive. Again, this reflects a broader ideological context which interprets restorative justice as a 'means of securing order in the future' (O'Malley, 2006, p. 222), rather than as 
a way to build positive social capital or address criminogenic social inequities. In other words, offenders were often included instrumentally - in the service of victims or society rather than because they were people with needs that the police and process might meet. This corresponds with a cultural quality within the police institution: suspects and offenders are 'police property' to whom, rather than for or with whom, policing is done (Waddington, 1999).

At the case-level, this created risks for (often, young) offenders who usually played only a passive role in practices which were dominated by others and which typically prioritised victims' participation and desires. Processes and outcomes that empowered or provided material or social support for offenders were in a minority of descriptions. In the many cases where the victims and officers negotiated outcomes among themselves, offenders were reliant on those parties reaching a proportionate and achievable conclusion, as this might represent their only chance for diversion from a higher disposal or prosecution.

Christie (2010) warned that 'victim power amplified with state power would indeed become a strong driving force towards a more punitive society' (p. 118). Advocates of restorative justice must not only ask how to persuade the police to use it, but how they might 'accomplish a greater extent of participatory justice, without losing important protective devices within our recent system' (Christie, 1982, p. 110; see also Levrant et al., 1999 on the potential for restorative justice to serve regressive goals). Yet, respondents described another constraint as a barrier to the collective deliberation of mutually beneficial outcomes: time.

\section{Restorative justice as demand management}

The operational imperative of demand management also shaped the use of restorative justice. At both forces, virtually all respondents conveyed that declining budgets and staffing levels informed its development. Accordingly, descriptions of practice suggested that dialogue and collective decision-making were regularly neglected in favour of quicker, more coercive and police-dominated resolutions. Drawing on seminal remarks by Skolnick (1966) regarding the tensions between efficiency and legality, these findings suggest that the pressure on officers to resolve cases quickly meant that they often acted efficiently rather than restoratively when the two norms were in conflict.

In both forces, respondents reported being motivated to develop or use restorative justice to save time. The view that this helped avoid the more resource-intensive options of arrest and prosecution was especially prevalent in Gloucestershire, where a senior respondent stated:

The big win from the police view is that a lot less police time is used. [...] We've seen some quite significant drops in our custody usage [which] is quite expensive and labour intensive.

Police policymaker, Gloucestershire

Similarly, one officer from Gloucestershire noted that restorative justice 'reduces paperwork and, in the long run, rules out having to go to court.' These statements reflected the close association in Gloucestershire of restorative justice with community resolutions, an informal disposal that was the only disposal alongside which Gloucestershire's officers could use restorative justice, and that Gloucestershire required its officers to deliver as 
Level 1 or Level 2 restorative justice. This led to restorative justice becoming synonymous with the informal resolution of cases - albeit, with the consent of both parties required.

Correspondingly, most described cases seemed to involve little stakeholder participation, beyond the minimum required to convince the victim to agree to informal resolution. Officers commonly reported having brief meetings with each party, seeking the parties' consent to resolve the case without formal processing, and using the offer of reparation or the prospect of a worse alterative as 'carrots' and 'sticks'. Their stories were evocative of the coercive, police-dominated approaches to Level 1 observed in other English forces (e.g., Cutress, 2015; Walters, 2014) and derided by Strang and Sherman (2015) as an 'evidence-free innovation' (p. 19) for lacking dialogue and collective decisionmaking among victims and offenders. Reiner (2010, p. 144) characterised police 'craft' as using 'the background possibility of legitimate coercion so skilfully that it never needs to be foregrounded.' In other words, police culture may be favourably disposed to negotiating order informally when possible, but this is inseparable from the underlying threat of coercion or use of lawful powers. This means that citizens have little choice but to accept the police's preferences in the administration of restorative processes, even if hastily arranged and performed with demand management as the primary goal.

That being said, in Durham, respondents were more likely than in Gloucestershire to state that efficiency gains related to their use of dialogic approaches to reduce reoffending and resolve conflict for the long-term. For example, one policymaker asserted:

If we target people who have had long running disputes and who repeatedly call on us, then that can be stemmed in maybe one or two meetings. Perhaps a lot of preparatory work before that and some work after the intervention, too, but I see a real role in terms of demand management. Police policymaker, Durham

Most other respondents in Durham similarly associated restorative justice with dialogue, and dialogue with effective prevention of future harm. This corresponded with much greater use of dialogic processes among descriptions of practice in Durham, compared to Gloucestershire. By implication, it is possible to train police and frame restorative policing in ways that encourage or enable officers to invest time in facilitating victim-offender dialogue to achieve longer-term efficiency gains - even though they may have the discretion and other incentives not to do so.

Still, the overriding imperative of demand management meant that in Durham, too, there were reports of practices that only involved a brief process of some kind. Several policymakers and experienced police facilitators pointed to 'cuffed' practices, inferring that the responsible officer offered the easiest, rather than most appropriate, responses. For example, some officers opted only to offer participants the possibility to apologise quickly and on the spot, or provide a short, written apology. The association of restorative justice with communication between the parties did not ensure that officers would always enable the parties to discuss what happened or determine collectively how to move forward.

These data serve to illuminate the gap between the policing and restorative lenses. From a restorative perspective, such cases represent a substantial deviation from best practice; from a policing perspective, however, they may be proportionate responses to minor incidents. One officer from Durham described facilitating an instant (Level 1), faceto-face apology, without further discussion between the parties, from three children who 
scared an elderly person by throwing snowballs at their house. The officer obtained what they believed were genuine apologies and assurances of future behaviour, and the complainant consented to the officer taking no further action upon receiving the apology. Where the officer saw a convenient, even optimal, policing response, restorative justice purists might see a missed opportunity for the parties to learn about each other's situations, build a positive relationship, and identify and respond to their needs. The elderly resident might have felt lonely and vulnerable, or scared of local young people following another incident; the young people may have innocently, but problematically, lacked empathy for the elderly, and had limited opportunities for more constructive activities. Moreover, the officer did not prepare the elderly person for the meeting: they caught the young people near the scene, bringing them to the front door without even communicating their imminent arrival to the resident. From a restorative justice perspective, this is anathema to best practice. From a police perspective, they closed the case to the satisfaction of all parties.

This illustrates how restorative policing reflects the manner in which restorative justice is integrated into operational routines. For example, research has found that restorative cautioning schemes emphasise offender deterrence - unsurprising, perhaps, if deterrence is already the core purpose of cautioning (Hoyle et al., 2002; O'Mahony et al., 2002). Likewise, to the extent that Level $1 \mathrm{RJ}$ represents an attempt to integrate restorative justice into the police's on-street 'peacekeeping' activities, we should not be surprised if the police seek to achieve quick resolutions using a spectrum of more or less coercive dispute resolution tactics (Sykes \& Brent, 1983). In other words, restorative justice seems to inform rather than transform whichever area of policing into which it is integrated, as officers try to balance new expectations against underlying constraints and embedded ways of working in a given aspect of their operational role.

This may help explain the dynamics of victim engagement emerging from the data. The requirement that community resolutions must be restorative meant that, if nothing else, the victim had to consent to an informal resolution. As such, at least on paper, virtually every restorative process was concluded with the victim's agreement. This could represent a substantial shift towards victim participation, as it removed (in theory) officers' discretion to decide unilaterally to resolve a case informally. An alternative reading is that victims were instrumentalised 'in the service of system efficiency' (Crawford, 2000, p. 292), with police using the veneer of helping victims to legitimise their efforts to achieve other goals (Ashworth, 2000). In this case, the rhetoric of restorative justice may give the impression that 'something is being done for victims' (Warner \& Gawlik, 2003, p. 73), while in practice, Level 1 restorative justice often offered little in the way of social, emotional or material support, but enabled rapid case closure. On the other side of the coin, that victims must consent to informal resolution remains problematic if a punitive victim is all that stands between an offender and a proportionate disposal. Certain risks of police-led restorative justice are intrinsically linked to their position within the criminal justice process, rather than exclusively being produced by poor practice.

Restorative justice enabled officers who were motivated to do so, to engage meaningfully with victims and invest time in solving problems to reap rewards in the long term. Yet, a restorative philosophy was only one among many factors that shaped officers' discretion in practice. 


\section{Restorative justice as managed empowerment}

Effective restorative processes are characterised by stakeholder empowerment, in that victims and offenders can shape the process according to their needs (Richards, 2011) and exert influence over outcomes (Barton, 2000, 2003; Zimmerman, 1995). Facilitators must exercise their discretion in skilled, creative ways to balance and maximise the parties' empowerment, and otherwise to administer the process according to key restorative values (Chapman, 2012). Yet, the data suggest that officers often exercised their discretion to achieve the organisational goals of victim satisfaction - interpreted as the victim consenting to resolve the case informally - and to manage the demand on their time. This speaks to the tension identified by Clamp and Paterson (2017): restorative justice requires the police to act as 'silent stakeholders rather than decision-makers' (p. 300), but they are reluctant to relinquish their closely-guarded authority and face various pressures and incentives not to do so.

Police facilitators kept control over their response to crime and conflict in a variety of ways, in addition to those already described. They could decide, for example, whether to offer restorative justice in the first place. No respondent reported offering it all the time, nor that the absence of an offer was ever challenged. When officers did offer restorative justice, they could maintain control by offering only indirect communication, enabling themselves to regulate the flow of information and affording citizens few opportunities to shape the process according to their own needs. For example, officers reported using their intermediary position to focus on and direct outcome selection, without giving the parties a chance to express their feelings or ask questions of each other. This corresponds with previous research indicating that the police are usually task- and outcome-oriented, rather than concerned with ensuring that the process is experienced as fair and legitimate (Tyler, 2006). This has been found in other restorative justice research on hybrid restorative-traditional processes, where time and resource constraints mean that case closure and agreement are prioritised over dialogue (Arrigo, 2004; Barnes, 2015; Crawford, 2006; McStravick, 2018).

Similarly, if the parties were enabled to communicate directly, officers seldom reported inviting other stakeholders (such as family members) to participate. The main barrier to this seemed to be the time required to organise the process, as one facilitator noted:

I think the more things you bring in, the more complicated it gets. Already, it's like herding cats trying to get everything together. [...] Do I want to get it done or not? If the answer is yes, include as few people as possible. Police facilitator, Durham

This exemplifies the tensions inherent in restorative policing. Research suggests that victims and offenders usually experience the process as more satisfying and fair if a family member participates (McCold \& Wachtel, 2002). Yet, police respondents felt under pressure to 'get things done' and exercised their discretion to provide limited opportunities for wider stakeholder participation, helping them maintain control.

Many police facilitators also reported feeling unable to relinquish control over outcome decisions, fearing that victims would select disproportionate outcomes. This reflects a responsibility held by all facilitators: to balance the rights and empowerment of participants. Barton (2000) describes empowerment in restorative justice as 'bounded' 
and 'directed' (pp. 2-4) because facilitators must exercise some control over the process to ensure adherence to shared norms and restorative values. Police facilitators described feeling this pressure especially keenly, noting that they facilitated not just on behalf of the participants, but as representatives of their force, the criminal justice system and society as a whole - all of whom, according to these officers, had an interest in certain outcomes. Indeed, some officers reported suggesting or even seeking to mandate certain outcomes to achieve 'justice', which they seemingly understood as linked to their role in representing wider society. This illustrates the plethora of interests that police officers, as justice practitioners, may feel responsible for balancing within their restorative justice facilitation, as in their day-to-day work.

Implicit in Barton's analysis (Barton, 2000) is the presumption that the facilitator is able and motivated to act in accordance with a predefined set of restorative values, circumscribing participant empowerment only to the extent necessary to realise these values. In a system where criminal justice practitioners are responsible for facilitation, however, they must respond to an assortment of competing imperatives which flow as much or more from the norms, rationales, goals and priorities of the organisations and structures within which they work, as they do from the theoretical restorative framework (Blad, 2006; Crawford, 2006). The police culture is well embedded and emerges as the sociopolitical setting in which policing occurs, interacts with the knowledge and assumptions underlying the police institution (Chan, 1996). Assuming that the introduction of restorative justice cannot instantaneously transform this, we should anticipate that restorative policing would reflect prevailing elements of this culture.

At the same time, the current study adds weight to the idea that introducing restorative justice can influence how the police exercise their discretion. The data suggest that respondents usually neither enabled nor denied participant empowerment entirely when facilitating. Rather, one might describe them as managing participant empowerment to balance the competing goals and varied interests, as perceived by officers, of all the stakeholders to their work.

This concept of 'managed empowerment' appears elsewhere in the literature on efforts to encourage public professionals to empower citizens. In her research on the role of healthcare professionals in supporting patients to make treatment decisions, Davey (2015) argues that patient empowerment is never absolute, because of the role that professionals necessarily play as 'knowledge brokers', 'ethical agents' and 'enablers' (p. 228). As 'knowledge brokers', they act as gatekeepers to information and to the options available to patients. As 'ethical agents', they remain responsible for ensuring fair and equitable outcomes which maximise patient wellbeing. Finally, as 'enablers', they are tasked with providing patients with support and resources and facilitating informed consent. Davey argued that power imbalances between professionals and patients act as barriers to deprofessionalised decision-making. Moreover, these imbalances are intrinsic and structural, arising from the parties' relationship and the institutional context within which healthcare services are provided.

This framework applies equally to, and has substantial implications for our expectations of, restorative policing. Restorative policing represents an attempt to encourage the police to devolve their decision-making authority to citizens. This deprofessionalisation requires officers to empower citizens to act autonomously and make their own decisions. 
Yet, the police remain responsible for informing victim and offenders about their options, ensuring that processes and outcomes accord with their expertise and their legal, ethical, organisational and professional responsibilities, and providing a facilitation capacity. In Davey's study (Davey, 2015), professionals:

[...] adopt[ed] managed empowerment as an expedient means to enable the patient to make 'any kind' of choice as long as it aligns with (or is pre-sanctioned by) the [healthcare professional]. (pp. 261-262)

In Durham and Gloucestershire, the police likewise held and often exercised a veto over citizen empowerment - a veto that, again, all restorative justice facilitators have. Yet, police officers used this not only to maximise the empowerment of participants, but to balance this empowerment against the norms, goals and priorities of their profession and institution. Ultimately, restorative policing was whatever the officer decided to do when seeking to strike this balance in a given case, as long as their actions qualified as restorative within their understanding of the concept and their force's bureaucratic framework.

\section{Conclusions and implications for restorative policing and restorative justice theory}

Advocates often claim that restorative justice can help remedy certain salient limitations of modern approaches to criminal justice. Some present restorative justice as a process which is more empowering, inclusive and responsive than conventional justice mechanisms, enabling those with the greatest stake in an offence to participate in addressing and repairing the harm done (Braithwaite, 2002; Schiff, 2007). Others believe that we can use a restorative framework to transform societal responses to crime and justice altogether (Wright, 2008).

This research illustrates how, in practice, justice agencies dilute restorative justice in ways that mirror their goals and priorities. Research has long shown how institutionalising restorative justice results in its principles being sacrificed in ways that affect participants' experiences of the process (Blad, 2006; Crawford, 2006; Daly, 2003). As Daly (2003) noted, when mainstreaming restorative justice, 'we should expect to see organisational routines, administrative efficiency and professional interests trumping justice ideals' (p. 231). Moreover, the malleability of restorative justice means that we should expect its interpretation - and the risks inherent therein - to vary according to the qualities of the setting in which it is implemented.

The current study showed what this looked like in two English police forces in 2015, where there was pressure simultaneously to provide better services to victims and to cope with declining resources. Framing restorative justice as something that helped with these issues may have made it more politically palatable under populist punitiveness (Acton, 2015) and austerity (Shewan, 2010). Yet, this may have come at the cost of important restorative principles, such as equality of concern for the parties and a focus on enabling dialogue between them.

At the same time, differences in practices between Durham and Gloucestershire suggest that it is possible to promote dialogic approaches in the police through training and the framing of restorative justice as dialogue. This might help fill a gap identified by 
Sykes and Brent (1983) and O'Neill (2014): the police devote considerable time to negotiating and reacting to conflict, without much training in conflict resolution skills. We know that the police mostly respond to low-level crime and non-crime conflict and often try to use persuasion rather than force when doing so (Bittner, 1990; Sykes \& Brent, 1983; Wilson, 1968). Restorative justice can inform police discretion to support 'the craft of effective policing' (Reiner, 2010, p. 144) by helping the police to minimise the need for recourse to their legal powers. As such, widespread training in dialogic practices could encourage a move to a 'restorative peacekeeping', in which the police adopt a participatory, harm-focused and evidence-based approach to maintaining order (Boba \& Crank, 2008; Clamp \& O'Mahony, 2019; Weitekamp et al., 2003).

One limitation of this approach relates to the risk of poor practice. Police officers exercise their discretion in a low-visibility, low-accountability environment. This means that there is little to prevent them from manipulating restorative processes to accomplish illegal or unethical goals (Levrant et al., 1999), or to ensure that they do not inadvertently put citizens at risk. Likewise, if either eventuality does occur, it is difficult to hold anyone accountable, or even to find out that it happened. This is especially important when the outcome of the process may have legal ramifications, such as a decision not to prosecute (Ashworth, 2000). It is important to remember, however, that these risks exist within the current policing approaches, which may not differ markedly from many of the lessparticipatory practices that are understood or recorded as restorative (Cutress, 2015). We ought to contextualise the standard to which we hold restorative approaches with reference to the levels of risk and other limitations of existing practice.

At the same time, calls to develop restorative justice to achieve certain goals need to be informed by evidence on the likelihood of those goals being attained. In Durham, policymakers were explicit that the scale of the training and expectations on the police to use restorative justice corresponded with their desire for those experiences to change the force's culture - despite the certainty that there would be risks along the way. The assumption that the benefits would more than compensate for the problems, underpinned their tolerance of short-term risks for anticipated medium- or long-term gains. Yet, whether these gains were realised is an empirical question, requiring both baseline and longitudinal data to begin to answer with any confidence.

Finally, change must also occur in how we conceptualise restorative justice and what we expect it to achieve. It is not necessary to pass judgement on the appropriate role of the state or police in restorative justice to observe that its theory is incomplete if it does not recognise the full breadth of interests that are present within most restorative justice processes. Restorative justice theory, as commonly portrayed, omits state actors from its models, focusing exclusively on victims, offenders and the community (however defined) as the 'real' stakeholders who can reclaim 'their' conflicts from the state (Johnstone, 2008). Yet, restorative policing epitomises the centrality of the state, as represented by public agencies and professionals, in contemporary, Western forms of restorative justice.

This study tallies with Daly (2003), Crawford (2006) and others who find that the gap between restorative justice theory and practice emerges partially as those responsible for its delivery seek to balance personal, institutional and restorative goals and priorities. Rather than ignore this, we might develop theory that recognises the state's role and influence on restorative justice. Such a framework could include the state's stake in restorative justice at three levels. Firstly, the state is an overarching system that sets the rules by which it governs 
and is delegated the task of balancing and representing the interests of all its citizens, by all its citizens. This means that it cannot organise or oversee any justice mechanism without both public and private interests in mind. Secondly, it delegates the tasks of balancing these interests in different contexts to institutions - in this case, police forces - which develop certain priorities, goals and cultures as they seek to fulfil their mandate while ensuring their self-preservation. Finally, the individuals who work for these institutions have a personal interest in the tasks and duties that constitute their working lives. For police officers, their safety, wellbeing, job satisfaction and career development, inter alia, depend on their success in responding to crime and conflict (Lipsky, 2010). They are invested, professionally and personally - that is, they hold a stake - in the incidents in which they intervene.

Unless we can mainstream restorative justice in a manner that disrupts the ultimate authority of the state, we must build the state and state actors into the framework that underpins its study and implementation, and into the benchmarks against which we set our expectations and measure its success.

\section{Notes}

1. The data presented in this section are drawn from statistics and documents obtained from each force; these and other data are described further in the following section on methodology.

2. Data from these eleven months are presented because this is the period of overlap between datasets collected from the two forces.

\section{Disclosure statement}

The author reported no potential conflict of interest.

\section{Funding}

This research was supported by an Economic and Social Research Council +3 Ph.D. Studentship.

\section{Notes on contributor}

Dr. Ian D. Marder joined the Maynooth University Department of Law as Lecturer/Assistant Professor in Criminology in May 2018. This paper draws on his Ph.D. research (University of Leeds), which explored the institutionalisation of restorative justice in English policing. Previously, he acted as Scientific Expert for the Council of Europe's Council for Penological Cooperation (2017-18) to draft Recommendation CM/Rec(2018)8 concerning restorative justice in criminal matters. $\mathrm{He}$ also worked as Research Associate (2018) for the University of Liverpool on the Public Engagement Strand of the N8 Policing Research Partnership.

\section{References}

Acton, E. (2015). Restorative justice a postcode lottery? Availability and quality of service. Safer Communities, 14(3), 120-125. https://doi.org/10.1108/SC-07-2015-0028

Angel, C., Sherman, L., Strang, H., Ariel, B., Bennett, S., Inkpen, N., Keane, A., \& Richmond, T. (2014). Short-term effects of restorative justice conferences on post-traumatic stress symptoms among 
robbery and burglary victims: A randomized controlled trial. Journal of Experimental Criminology, 10(3), 291-307. https://doi.org/10.1007/s11292-014-9200-0

Arrigo, B. (2004). Rethinking restorative and community justice: A postmodern enquiry. Contemporary Justice Review, 7(1), 91-100. https://doi.org/10.1080/1028258042000212049

Ashworth, A. (2000). Victims' rights, defendants' rights and criminal procedure. In A. Crawford \& J. Goodey (Eds.), Integrating a victim perspective within criminal justice (pp. 185-204). Ashgate. Association of Chief Police Officers. (2011). Restorative justice guidelines and minimum standards.

Barnes, O. (2015). Restorative justice in the criminal justice system: The McDonaldization of diversionary youth conferencing. Ulster University. Retrieved June 14, 2017, from http://ethos.bl.uk/ OrderDetails.do?uin=uk.bl.ethos.669225

Barton, C. (2000). Restorative justice empowerment. Australian Journal of Professional and Applied Ethics, 2(2), 1-22.

Barton, C. (2003). Restorative justice: The empowerment model. Hawkins Press.

Bayley, D., \& Bittner, E. (1984). Learning the skills of policing. Law and Contemporary Problems, 47(3), 35-59. https://doi.org/10.2307/1191686

Bazemore, G., \& Griffiths, C. (2003). Police reform, restorative justice and restorative policing. Police Practice and Research, 4(4), 335-346. https://doi.org/10.1080/15614260310001631244

Bittner, E. (1990). Aspects of police work. Northeastern University Press.

Blad, J. (2006). Institutionalising restorative justice? Transforming criminal justice? A critical view on the Netherlands. In I. Aertsen, T. Daems, \& L. Robert (Eds.), Institutionalising restorative justice (pp. 93-119). Willan Publishing.

Boba, R., \& Crank, J. (2008). Institutionalizing problem-oriented policing: rethinking problem solving, analysis and accountability. Police Practice and Research, 9(5), 379-393. https://doi.org/10.1080/ 15614260801980745

Boutellier, H. (2006). The vital context of restorative justice. In I. Aertsen, T. Daems, \& L. Roberts (Eds.), Institutionalising restorative justice (pp. 25-43). Willan Publishing.

Bowling, B., Phillips, C., Campbell, A., \& Docking, M. (2001). Policing and human rights: Eliminating discrimination, xenophobia, intolerance and the abuse of power from policework. United Nations Research Institute for Social Development. Retrieved April 01, 2017, from http://eprints.Ise.ac.uk/ 28367/1/Policing_and_Human_Rights_\%28author\%29.pdf

Braithwaite, J. (2002). Setting standards for restorative justice. British Journal of Criminology, 42(4), 563-577. https://doi.org/10.1093/bjc/42.3.563

Chan, J. (1996). Changing police culture. British Journal of Criminology, 36(1), 109-134. https://doi. org/10.1093/oxfordjournals.bjc.a014061

Chapman, T. (2012). Facilitating restorative conferences. In E. Zinsstag \& I. Vanfraechem (Eds.), Conferencing and restorative justice: International practices and perspectives (pp. 65-82). Oxford University Press.

Choongh, S. (1998). Policing the dross: A social disciplinary model of policing. British Journal of Criminology, 38(4), 623-634. https://doi.org/10.1093/bjc/38.4.623

Christie, N. (1982). Limits to Pain. Martin Robertson.

Christie, N. (2010). Victim movements at a crossroads. Punishment and Society, 12(1), 115-122. https://doi.org/10.1177/1462474509357978

Clamp, K., \& Paterson, C. (2013). An exploration of the role of leadership in restorative policing in England and Wales. In N. Erbe \& A. Normore (Eds.), Collective efficacy: Interdisciplinary perspectives on international leadership (pp. 293-307). Emerald Group Publishing Ltd.

Clamp, K., \& O'Mahony, D. (2019). Restorative policing provision across England and Wales in 2018. University of Nottingham. Retrieved October 10, 2019, from https://www.researchgate.net/pub lication/333286397_RESTORATIVE_POLICING_PROVISION_ACROSS_ENGLAND_AND_WALES_IN_ 2018

Clamp, K., \& Paterson, C. (2017). Restorative policing: Concepts, theory and practice. Routledge.

Crawford, A. (2000). Salient themes towards a victim perspective and the limitations of restorative justice: Some concluding comments. In A. Crawford \& J. Goodey (Eds.), Integrating a victim perspective within criminal justice (pp. 285-310). Ashgate. 
Crawford, A. (2006). Institutionalising restorative justice in a cold, punitive environment. In I. Aertsen, T. Daems, \& L. Robert (Eds.), Institutionalising restorative justice (pp. 120-150). Willan Publishing.

Crawford, A. (2010). Conceptual links and policy challenges (restorative justice and crime prevention: Presenting a theoretical explanation, an empirical analysis and the policy perspective). European Forum for Restorative Justice. Retrieved October 30, 2013, from http://euforumrj.org/assets/ upload/Restorative_Justice_and_Crime_Prevention_Final_report.pdf

Crocker, D. (2016). Balancing justice goals: Restorative justice practitioners' views. Contemporary Justice Review, 19(4), 462-478. https://doi.org/10.1080/10282580.2016.1226815

Cutress, L. (2015). The use of restorative justice by the police in England and Wales. University of Sheffield. Retrieved September 08, 2016, from http://etheses.whiterose.ac.uk/8811/

Daly, K. (2003). Mind the gap: Restorative justice in theory and practice. In A. Von Hirsch, J. Roberts, A. Bottoms, K. Roach, \& M. Schiff (Eds.), Restorative justice and criminal justice: Competing or reconcilable paradigms? (pp. 219-236). Hart Publishing.

Daly, K. (2016). What is restorative justice? Fresh answers to a vexed question. Victims and Offenders, 11(1), 9-29. https://doi.org/10.1080/15564886.2015.1107797

Davey, J. (2015). Health literacy: A hermeneutic study of New Zealand baby boomers. University of Waikato. Retrieved June 16, 2017, from https://waikato.researchgateway.ac.nz/bitstream/handle/ 10289/9591/thesis.pdf?sequence=3\&isAllowed $=y$

Delsol, R., \& Shiner, M. (2006). Regulating stop and search: A challenge for police and community relations in England and Wales. Critical Criminology, 14(3), 241-263. https://doi.org/10.1007/ s10612-006-9013-1

Duggan, M., \& Heap, V. (2014). Administrating victimization: The politics of anti-social behaviour and hate crime policy. Palgrave MacMillan.

Dzur, A. (2016). Conversations on restorative justice: A talk with Tim Chapman. Restorative Justice: An International Journal, 4(1), 115-129. https://doi.org/10.1080/20504721.2016.1148467

Fielding, N., \& Innes, M. (2006). Reassurance policing, community policing and measuring police performance. Policing and Society, 16(2), 127-145. https://doi.org/10.1080/10439460600662122

Garland, D. (2001). The culture of control: Crime and social order in contemporary society. Oxford University Press.

Gavrielides, T. (2017). The Victims' Directive and what victims want from restorative justice. Victims and Offenders, 12(1), 21-42. https://doi.org/10.1080/15564886.2014.982778

Goldstein, H. (1977). Policing a free society. Ballinger.

Goldstein, J. (1960). Police discretion not to invoke the criminal process: Low-visibility decisions in the administration of justice. The Yale Law Journal, 69(4), 543-594. https://doi.org/10.2307/ 794445

Gray, P. (2005). The politics of risk and young offenders' experiences of social exclusion and restorative justice. British Journal of Criminology, 45(6), 938-957. https://doi.org/10.1093/bjc/ azi018

Greene, D. (2013). Repeat performance: Is restorative justice another good reform gone bad? Contemporary Justice Review, 16(3), 359-390. https://doi.org/10.1080/10282580.2013.828912

Her Majesty's Inspectorate of Constabulary. (2014). State of policing: The annual assessment of policing in England and Wales, 2013/14. Her Majesty's Inspectorate of Constabulary. Retrieved July 11, 2017, from http://www.justiceinspectorates.gov.uk/hmic/wp-content/uploads/state-ofpolicing-13-14.pdf

Her Majesty's Inspectorate of Constabulary. (2016). Crime and policing comparator. Her majesty's Inspectorate of Constabulary. Retrieved May 06, 2016, from https://www.justiceinspectorates. gov.uk/hmic/crime-and-policing-comparator/

Hipple, N., \& McGarrell, E. (2008). Comparing police- and civilian-run family groups conferences. Policing: An International Journal of Police Strategies \& Management, 31(4), 553-577. https://doi. org/10.1108/13639510810910562

Home Office. (2013). A revised framework for recorded crime outcomes. Home Office. Retrieved March 17, 2014, from https://www.gov.uk/government/uploads/system/uploads/attachment_data/file/ 157796/consultation-response.pdf 
Home Office. (2017). Police workforce England and Wales statistics. Home Office. Retrieved July 09, 2017, from https://www.gov.uk/government/collections/police-workforce-england-and-wales

Hoyle, C., Young, R., \& Hill, R. (2002). Proceed with caution: An evaluation of the Thames Valley police initiative in restorative cautioning. Joseph Rowntree Foundation. Retrieved March 17, 2014, from http://www.jrf.org.uk/sites/files/jrf/1859353819.pdf

Hoyle, C. (2010). The case for restorative justice. In C. Hoyle \& C. Cuneen (Eds.), Debating restorative justice (pp. 1-100). Hart Publishing.

Hoyle, C. (2011). Restorative justice, victims and the police. In T. Newburn (Ed.), Handbook of policing (pp. 794-823). Willan Publishing.

Ikerd, T. (2007). Examining the institutionalization of problem-oriented policing: The Charlotte-Mecklenburg Police Department as a case study. University of Nebraska. Retrieved May 12, 2017, from http://search.proquest.com/openview/1a65210d6ab10d2a9d427ae0de209fd7/1? pq-origsite $=$ gscholar $\&$ cbl $=18750 \&$ diss $=y$

Innes, M. (2005). Why 'soft' policing is hard: On the curious development of reassurance policing, how it became neighbourhood policing and what this signifies about the politics of police reform. Journal of Community \& Applied Social Psychology, 15(3), 156-169. https://doi.org/10. $1002 /$ casp. 818

Institute for Criminal Policy Research. (2016). Report of a mapping exercise of restorative justice provision in England and Wales for the Restorative Justice Council. Birkbeck, University of London.Retrieved May 03, 2016, from https://www.rjc.org.uk/sites/default/files/resources/files/ ICPR\%20mapping\%20report\%20of\%20restorative\%20justice\%20provision.pdf

Johnstone, G. (2008). Restorative justice: Ideas, values, debates. Willan Publishing.

Karp, D. (2015). The little book of restorative justice for colleges and universities. Good Books.

Karstedt, S. (2011). Our sense of justice: Values, justice and punishment. In S. Parmentier, L. Walgrave, I. Aertsen, J. Maesschalck, \& L. Paoli (Eds.), The sparking discipline of criminology (pp. 33-58). Leuven University Press.

Kenney, J, \& Clairmont, D. (2009). Using the victim as both sword and shield: Ohe interactional dynamics of restorative justice sessions. Journal of Contemporary Ethnography, 38(3), 279-307.

Larsen, A. (2014). Restorative justice in the Australian criminal justice system (Australian Institute of Criminology). Australian Institute of Criminology. Retrieved March 29, 2014, from http://www.aic. gov.au/media_library/publications/rpp/rpp127.pdf

Larsson, B., Schofield, G., \& Biggart, L. (2018). The challenges for good practice in police-facilitated restorative justice for female offenders. International Journal of Restorative Justice, 1(1), 33-56. https://doi.org/10.5553/IJRJ/258908912018001001003

Laxminarayan, M. (2014). Accessibility and initiation of restorative justice. European Forum for Restorative Justice. Retrieved September 13, 2016, from http://euforumrj.org/assets/upload/ Accessibility_and_Initiation_of_RJ_website.pdf

Levrant, S., Cullen, F., Fulton, B., \& Wozniak, J. (1999). Reconsidering restorative justice: The corruption of benevolence revisited. Crime and Delinquency, 45(1), 3-27. https://doi.org/10.1177/ 0011128799045001001

Lipsky, M. (2010). Street level Bureaucracy: Dilemmas of the individual in public service. Russel Sage Foundation.

Lofty, M. (2002). Restorative policing. International Institute for Restorative Practices. Retrieved January 25, 2017, from http://www.iirp.edu/pdf/mn02_lofty.pdf

Mackay, R. (2006). The Institutionalization of principles in restorative justice: A case study from the UK. In I. Aertsen, T. Daems, \& L. Robert (Eds.), Institutionalizing restorative justice (pp. 194-215). Willan Publishing.

Matthews, R. (2006). Reintegrative shaming and restorative justice: Reconciliation or divorce? In I. Aertsen, T. Daems, \& L. Robert (Eds.), Institutionalising restorative justice (pp. 237-260). Willan Publishing.

McBarnet, D. (1981). Conviction: Law, the state and the construction of justice. Palgrave.

McCold, P. (1998). Police facilitated restorative conferencing: What the data show. International Institute for Restorative Practices. Retrieved February 19, 2013, from http://canada.iirp.org/ uploads/article_pdfs/policeconferencing.pdf 
McCold, P. (2000). Toward a mid-range theory of restorative criminal justice: A reply to the Maximalist model. Contemporary Justice Review, 3(4), 357-414.

McCold, P., \& Wachtel, T. (2002). Restorative justice theory validation. In E. Weitekamp \& H. Kerner (Eds.), Restorative justice: Theoretical foundations (pp. 110-142). Willan Publishing.

McConville, M., Sanders, A., \& Leng, R. (1991). The case for the prosecution. Routledge.

McStravick, D. (2018). Adult reparation panels and offender-centric meso-communities: An answer to the conundrum. International Journal of Restorative Justice, 1(1), 96-121. https://doi.org/10. 5553/IJRJ/258908912018001001006

Meadows, L., Albertson, K., Ellingworth, D., \& Senior, P. (2012). Evaluation of the South Yorkshire Restorative Justice Programme. Hallam Centre for Community Justice.

Ministry of Justice. (2013). 2013 Restorative justice action plan for the criminal justice system.

Ministry of Justice. (2015). Code of practice for victims of crime. Retrieved September 14, 2016, from https://www.gov.uk/government/uploads/system/uploads/attachment_data/file/476900/codeof-practice-for-victims-of-crime.PDF

Murray, W. (2012). Restorative justice facilitation: An appreciative inquiry into effective practice for Aotearoa/New Zealand facilitators. Auckland University of Technology. Retrieved August 11, 2014, from http://aut.researchgateway.ac.nz/bitstream/handle/10292/4683/MurrayWM.pdf? sequence $=5 \&$ is Allowed $=\mathrm{y}$

O'Mahony, D., \& Doak, J. (2013). Restorative justice and police-led cautioning. In G. Johnstone (Ed.), A restorative justice reader (pp. 134-145). Routledge.

O'Mahony, D., Chapman, T., \& Doak, J. (2002). Restorative cautioning: A study of police based restorative cautioning pilots in Northern Ireland. Northern Ireland Office.

O'Mahony, D., \& Doak, J. (2004). Restorative justice - Is more better? The experience of police-led restorative cautioning pilots in Northern Ireland. The Howard Journal of Criminal Justice, 43(5), 484-505. https://doi.org/10.1111/j.1468-2311.2004.00344.x

O'Mahony, D., \& Doak, J. (2017). Reimagining restorative justice. Hart Publishing.

O'Malley, P. (2004). The government of risks. In A. Sarat (Ed.), The blackwell companion to law and society (pp. 292-308). Blackwell Publishing.

O'Malley, P. (2006). Risk and restorative justice: Governing through the democratic minimisation of harms. In I. Aetsen, T. Daems, \& L. Robert (Eds.), Institutionalising Restorative Justice (pp. 216-236). Willan Publishing.

O'Neill, M. (2014). PCSOs as the paraprofessionals of policing: Findings and recommendations from a research project. Scottish Institute of Policing Research. Retrieved January 02, 2017, from http:// www.sipr.ac.uk/downloads/PCSO_project_report.pdf

Oliver, W. (2000). The third generation of community policing: Moving through innovation, diffusion and institutionalisation. Policing Quarterly, 3(4), 367-388.

Reiner, R. (2010). The politics of the police. Oxford University Press.

Restorative Justice Council. (2011). Best practice guidance for restorative practice.

Richards, K. (2011). Restorative justice and "empowerment": Producing and governing active subjects through "empowering" practices. Critical Criminology, 19(1), 91-105. https://doi.org/10. 1007/s10612-010-9106-8

Rosenblatt, F. (2015). The role of community in restorative justice. Routledge.

Sanders, A., Young, R., \& Burton, M. (2010). Criminal justice. Oxford University Press.

Schiff, M. (2007). Satisfying the needs and interests of stakeholders. In G. Johnstone \& D. Van Ness (Eds.), Handbook of restorative justice (pp. 228-264). Willan Publishing.

Shapland, J., Crawford, A., Gray, E., \& Burn, D. (2017). Developing restorative policing in Humberside, South Yorkshire and West Yorkshire. University of Sheffield. Retrieved February 23, 2017, from https://www.sheffield.ac.uk/polopoly_fs/1.682936!/file/developing-restorative-policing-stage1report.pdf

Shapland, J., Robinson, G., \& Sorsby, A. (2011). Restorative justice in practice: Evaluating what works for vicitms and offenders. Routledge.

Shearing, C., \& Ericson, R. (1991). Culture as figurative action. British Journal of Sociology, 42(4), 481-506. https://doi.org/10.2307/591444 
Sherman, L. (2013). The rise of evidence-based policing: Targeting, testing and tracking. Crime and Justice, 42(1), 377-451. https://doi.org/10.1086/670819

Sherman, L., Strang, H., Barnes, G., Woods, D., Bennet, S., Inkpen, N., ... Slothower, M. (2015). Twelve experiments in restorative justice: The Jerry Lee program of randomized trials of restorative justice conferences. Journal of Experimental Criminology, 11(4), 501-540. https://doi.org/10.1007/ s11292-015-9247-6

Sherman, L., Strang, H., Barnes, J., Braithwaite, J., Inkpen, M., \& Teh, M. (1998). Experiments in Restorative Policing: A Progress Report on the Canberra Reintegrative Shaming Experiements (RISE). Australian National University.

Shewan, G. (2010). A business case for restorative justice and policing. ACPO.

Skogan, W. (2006). Police and community in Chicago: A Tale of Three Cities (Vol. 1). Oxford University Press.

Skolnick, J. (1966). Justice Without Trial. Wiley.

Skolnick, J., \& Bayley, D. (1988). Community policing: Issues and practices around the world. National Institute of Justice.

Stockdale, K. (2015). The implementation of restorative justice policy: A case study of one police force in England and Wales. University of Durham. Retrieved September 08, 2016 from, http://etheses.dur. ac.uk/11331/

Strang, H., \& Sherman, L. (2015). The morality of evidence. Restorative Justice, 3(1), 6-27. https://doi. org/10.1080/20504721.2015.1049869

Strang, H., Sherman, L., Mayo-Wilson, E., Woods, D., \& Ariel, B. (2013). Restorative Justice Conferencing (RJC) Using Face-to-Face Meetings of Offenders and Victims: Effects on Offender Recidivism and Victim Satisfaction. A Systematic Review. The Campbell Collaboration.

Sykes, R., \& Brent, R. (1983). Policing: A social behaviorist perspective. Rutgers University Press.

Tilley, N. (2003). Community policing, problem-oriented policing and intelligence-led policing. In T. Newburn (Ed.), Handbook of Policing (pp. 311-339). Willan Publishing.

Tyler, T. (2006). Restorative justice and procedural justice: Dealing with rule breaking. Journal of Social Issues, 62(2), 307-326. https://doi.org/10.1111/j.1540-4560.2006.00452.x

Vanfraechem, I. (2009). Restorative policing: In pursuit of principles. Journal of Police Studies, 11(2), 39-64.

Waddington, P. (1999). Policing citizens. UCL Press.

Walgrave, L. (2012). The need for clarity about restorative justice conferences. In E. Zinsstag \& I. Vanfraechem (Eds.), Conferencing and restorative justice: International practices and perspectives (pp. 33-46). Oxford University Press.

Walters, M. (2014). Hate crime and restorative justice: Exploring causes, repairing harms. Oxford University Press.

Warner, K., \& Gawlik, J. (2003). Mandatory compensation orders for crime victims and the rhetoric of restorative justice. Australian and New Zealand Journal of Criminology, 36(1), 60-76. https://doi. org/10.1375/acri.36.1.60

Weitekamp, E., Kerner, H., \& Meier, U. (2003). Community and problem-oriented policing in the context of restorative justice. In E. Weitekamp \& H. Kerner (Eds.), Restorative justice in context: International practice and directions (pp. 304-326). Willan.

Wilson, J. (1968). Dilemmas of police administration. Public Administration Review, 28(5), 407-417. https://doi.org/10.2307/973756

Wright, M. (2008). Making good: Prisons, punishment and beyond. Waterside Press.

Zimmerman, M. (1995). Psychological empowerment: Issues and illustrations. American Journal of Community Psychology, 5(581-599), 23. 